\title{
Introducción al debate: Monumentos en Latinoamérica: Entre la épica patria y la insurrección
}

\section{Francisca Márquez}

\author{
(2) OpenEdition \\ Journals \\ Electronic version \\ URL: https://journals.openedition.org/corpusarchivos/4505 \\ DOI: 10.4000/corpusarchivos.4505 \\ ISSN: 1853-8037 \\ Publisher \\ Diego Escolar

\section{Electronic reference} \\ Francisca Márquez, «Introducción al debate: Monumentos en Latinoamérica: Entre la épica patria y la \\ insurrección », Corpus [En línea], Vol. 11, №. 1 | 2021, Publicado el 29 junio 2021, consultado el 03 julio \\ 2021. URL: http://journals.openedition.org/corpusarchivos/4505 ; DOI: https://doi.org/10.4000/ \\ corpusarchivos. 4505
}

\footnotetext{
This text was automatically generated on 3 July 2021. 


\title{
Introducción al debate: Monumentos en Latinoamérica: Entre la épica patria y la insurrección
}

\author{
Francisca Márquez
}

1 El debate que presentamos en este número de Revista Corpus propone leer en claves históricas y culturales, los gestos y expresiones desmonumentalizadores que ocurren desde hace algunas décadas en nuestras ciudades latinoamericanas. En este debate participamos catorce personas, historiadores, antropólogos/as y fotógrafos que viven e investigan en países con historias y culturas tan diversas como México, Colombia, Ecuador, Brasil, Argentina y Chile. ${ }^{1}$ Sociedades que son y han sido testigos y agentes de procesos de derrumbe, martillazos, ahorcamientos e intervenciones de monumentos y estatuas emplazadas en los espacios públicos de sus ciudades.

2 Tal como se muestra en este debate, el inventario iconoclasta de los monumentos caídos en América Latina es vasto y promete seguir creciendo. A pesar de que la definición e instalación de la monumentalidad en los espacios públicos ha sido históricamente privilegio del Estado y su institucionalidad, en las últimas décadas, esculturas, bustos y edificios patrimoniales se han visto sometidos a una cierta antropofagia ritual (Métraux, 2011) por parte de hordas enardecidas de ciudadanos. En este inventario de los monumentos, derrumbados y devorados, se cuentan las estatuas de Cristóbal Colón; el busto del conquistador Pedro de Valdivia "empalado" a los pies de la estatua del cacique Lautaro en Temuco; el monumento derribado del emprendedor y exterminador de fueguinos José Menéndez, depositado a los pies de la estatua del indio patagón en la Plaza de Armas de Punta Arenas; y más recientemente la icónica estatua de Sebastián de Belalcázar de Cali por parte de comunidades indígenas, entre muchos otros. ${ }^{2}$ Todos ellos son parte del botín de guerra de las revueltas e insurrecciones del siglo XXI que arrancan del espacio público los recordatorios que, en nombre del progreso y la civilización, asientan el poder colonial, patriarcal, racista y clasista. 


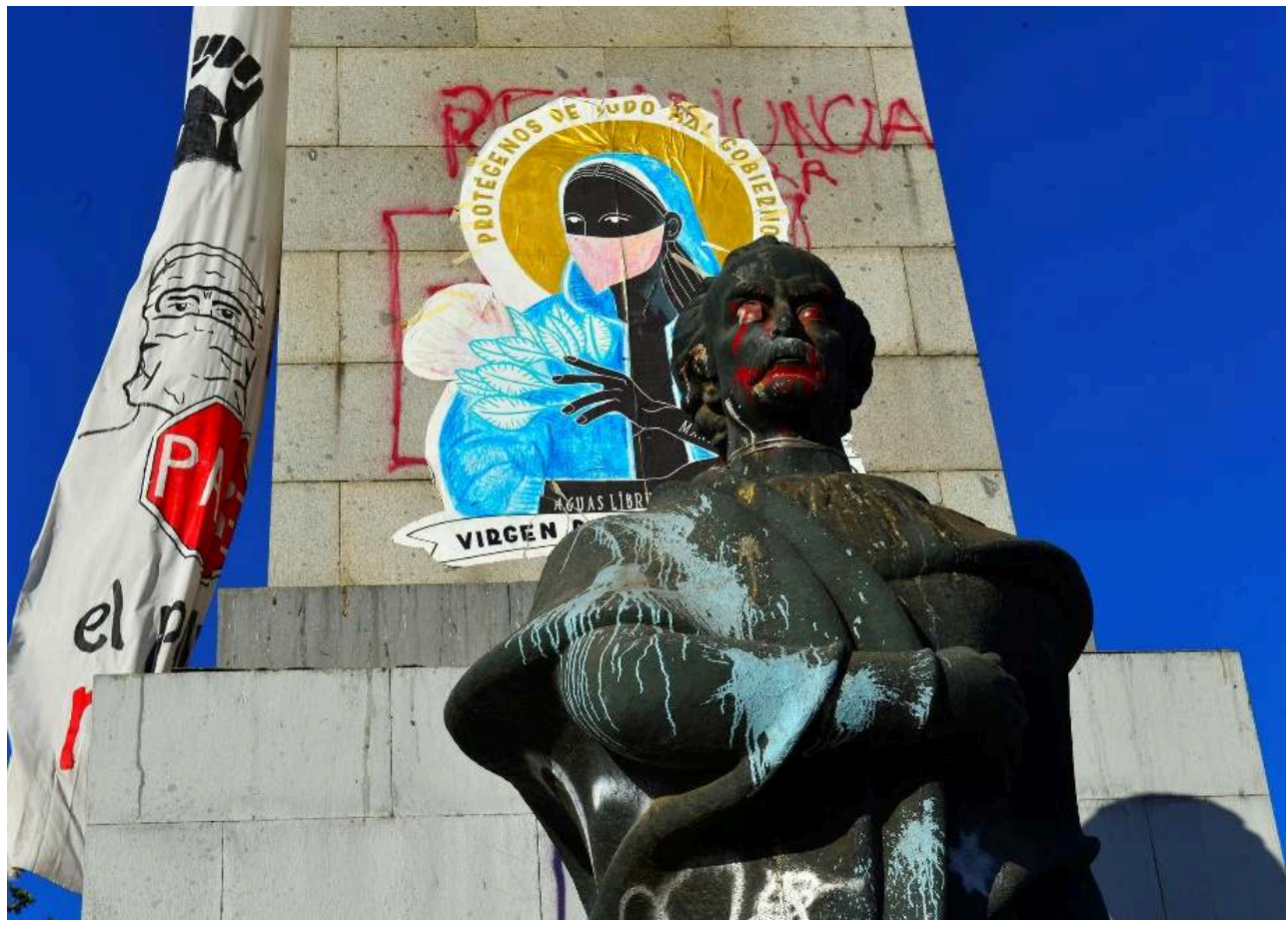

Imagen $\mathrm{N}^{\circ} 1$. Monumento al expresidente Balmaceda con sus ojos mutilados y resguardado por la «VIRGEN DE LAS BARRICADAS» y la bandera de los jóvenes de la Primera Línea. Fuente: Alvaro Hoppe, Fondecyt 1180352, 2020.

3 Junto a estos actos de antropofagia ritual, sin embargo, nacen también los contramonumentos. Es el caso del busto de Milanka, mujer diaguita, y que se instala luego del derribamiento del monumento al conquistador español Francisco de Aguirre, en la ciudad de La Serena; los tres tótem o esculturas de madera representando al pueblo mapuche, diaguita y selk'nam frente al monumento del General Baquedano en Plaza Dignidad, Santiago; el monumento al Inca Cahuide resistiendo al español en la batalla de Saqsaywaman, Perú; o el busto a Comanche, el gran líder afrodescendiente del barrio marginal El Cartucho en Bogotá. Son los contra-monumentos, monumentos incómodos o momentos negativos, que nos recuerdan que el relato de la nación se hace también de dolorosa subalternidad; y que la historia, ni la más violenta, fagocita de todas las memorias. Por el contrario, la historia siempre puede ser revisitada, subvertida y actualizada no solo para remover el horror de los pedestales sino también para construir sus contramonumentos y homenajear a las víctimas de dicho poder. 


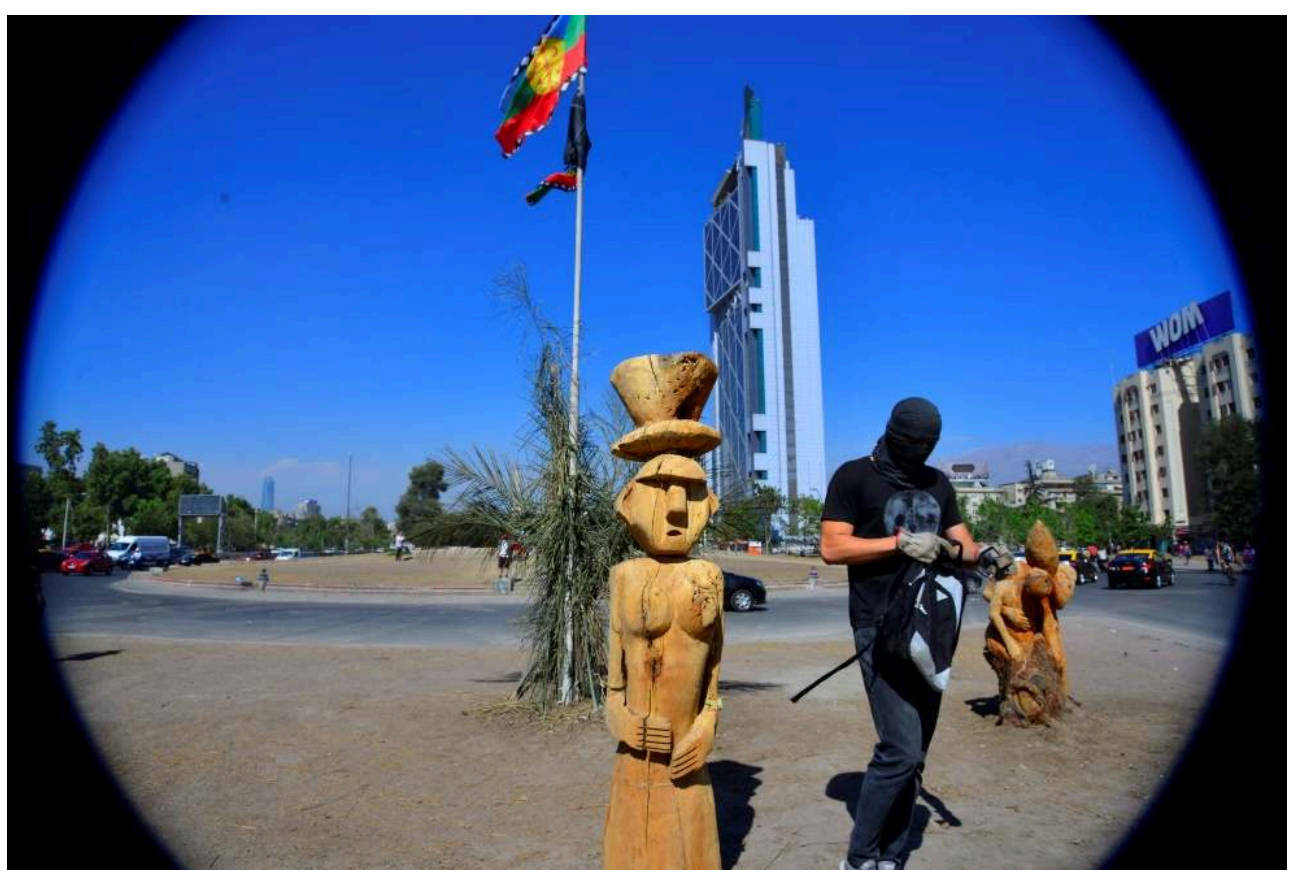

Imagen $N^{\circ}$ 2. Esculturas de madera en Plaza Dignidad, una domamüll y un espíritu selk’́nam; flamea la wenufoye. Elaboración del Colectivo de Artesanos Originarios. Fuente: Alvaro Hoppe, Fondecyt $1180352,2020$.

4 Sea cual sea la puesta en escena de los gestos iconoclastas y antropofágicos, lo cierto es que la hipertrofia del derrumbe y de la materialidad trizada de las estatuas habla de la complejidad del gesto desmonumentalizador. En efecto, el destrozo que nos informa el escombro o la grieta en el monumento no es solo borramiento es, también, toma de posición. El monumento descabezado, rayado, arrastrado, colgado, ahogado o reinventado, nos remite a un cierto espesor significante complejo de interpretar. A medio camino entre la materialidad derruida (la cosa) y sus significados (objeto), la materialidad descabezada y fragmentada nos invita a preguntarnos por el carácter de fetiche que en ella se encarna. Esto nos invita a entrar en las complejidades del valor de uso de este monumento, sus desplazamientos y transformaciones. Un sistema de uso tan rígido culturalmente, que la simple transferencia de un objeto de una esfera a otra basta para hacerlo irreconocible e inquietante (Agamben, 2006). Al igual que los juguetes, las estatuas pueden ser desmembradas y reducidas a fragmentos para así perder su pedagogía original, y ser usadas como campo de batalla o botín de guerra. Mil veces restaurados y patrimonializados, los monumentos y estatuas constituyen un buen ejemplo de este proceso de (des)fechitización de los objetos, ordenando y controlando nuestra experiencia de ser-en-el-mundo (Agamben, 2006; Gordillo, 2018). Buen ejemplo también de cómo el fetiche no tiene una sola lectura posible y cómo el exceso de historia monumental, como señala Nietzsche (2008 [1874]), es también la negación de su crítica.

5 En síntesis, sean cuales sean los escombros que los procesos de insurrección hayan dejado, estos siempre -como materialidades residuales que son- desordenan y desconciertan a nuestras ciudades y a nuestras naciones. La disputa que las prácticas iconoclastas provocan en la narrativa-monumental-patria tensionan la definición de lo que merece ser recordado y resguardado. La pintura, limpieza o blindaje de estatuas y monumentos difícilmente borrarán ese entramado de sentires y demandas que configuran el paisaje de la protesta. La pregunta es entonces, cómo repensar las 
estatuas, los monumentos y espacios públicos, en función de estos gestos y voces de la revuelta y el malestar. Aprender a leer y a escuchar estos gestos insurrectos e iconoclastas, como libros o pizarrones que contienen los manifiestos de la sociedad que queremos, parece una urgencia de estos tiempos.

Las siguientes preguntas orientan el debate que aquí proponemos: ¿Cuáles son los significados del gesto y del repertorio desmonumentalizador en Latinoamérica? ¿A quiénes violenta y ofende la presencia y visibilidad pública de estos monumentos, qué memorias y recuerdos ellos evocan? ¿Cómo participan y aportan en este proceso de reescritura de la historia los contra monumentos? ¿Cómo se tensionan las políticas patrimonializantes y urbanas a partir de estos acontecimientos y expresiones artísticas y performáticas? ¿Qué claves teóricas y conceptuales contribuyen a comprender estos procesos de desmonumentalización decolonial?

\section{BIBLIOGRAPHY}

Agamben, G. (2006). Estancias. La palabra y el fantasma en la cultura occidental. Valencia: Pretextos.

Gordillo, G. (2018). Escombros del progreso. Buenos Aires: Siglo XXI.

Métraux, Alfred. (2011 [1928]). Antropofagia y Cultura. Apostilla por Raúl Antelo. Buenos Aires: El cuenco de plata. Cuadernos de plata.

Nietzche, F. (2008 [1874]). II Intempestiva: Sobre la utilidad y el perjuicio de la historia para la vid. Madrid: Editorial Gredos.

\section{NOTES}

1. En este debate se retoman resultados de la investigación Fondecyt 1180352, Ruinas Urbanas. Réplicas de memorias en ciudades latinoamericanas.

2. Aunque el debate aquí propuesto aborda fundamentalmente acontecimientos ocurridos en Latino y Centroamérica, no podemos desconocer la serie de eventos que a lo largo de la historia se suceden en otros continentes. Tal es el caso de la estatua de Luis XIV en el Versalles posrevolucionario (1789/1799); Stalin en 1956 y 2010; Saddam Hussein el 2013; Lenin el 2013. Más recientemente, tras la muerte de George Floyd (2020) por parte de un policía blanco en Estados Unidos, una serie de otras estatuas fueron derribadas: Estatuas de Cristóbal Colón en Boston, Miami, Baltimore, Richmond, Minneapolis, entre otras ciudades; en Bristol, la estatua del comerciante de esclavos del siglo XVII, Edward Colston, entre otros. A ello debiera sumarse el retiro de estatuas por parte de autoridades, como una forma de desmonumentalización oficial para evitar el gesto popular o, simplemente, hacer desaparecer íconos incómodos, como ocurrió con el busto de José Martí en el municipio de derecha en Santiago de Chile. 


\section{AUTHOR}

FRANCISCA MÁRQUEZ

Universidad Alberto Hurtado, Chile.

Correo electrónico: fmarquezb@gmail.com 